\title{
Diálogos entre padres y adolescentes sobre sexualidad: discursos morales y médicos en la reproducción de las desigualdades de género*
}

Daniel Eduardo Jones ${ }^{1}$

JONES, D.E. Dialogue between parents and teenagers about sexuality: moral and medical discourse reproducing gender inequalities. Interface - Comunic., Saude, Educ., v.14, n.32, p.171-82, jan./mar. 2010.

Teenage girls and boys construct certain dimensions of their sexuality through dialogue with adults, who transmit values and standards to them. This paper analyzes conversations about sexuality between teenagers and their parents, in which medical and moral discursive registers are interlinked. The study was based on 46 individual interviews with boys and girls between 15 and 19 years of age, from middle-level socioeconomic strata who were living in Trelew (a city of 90,000 inhabitants in Patagonia, Argentina) and attending high school. To explain differences in the dynamics of dialogue between the teenage girls and boys, we constructed the notions of parental control over teenage girls' sexuality and material and discursive omnipresence of condoms. These notions show how this dialogue with adults is crossed by unequal gender expectations that are, in turn, reinforced by these adults.

Keywords: Teenagers. Sexuality. Dialogue with parents.
As mulheres e os homens adolescentes constroem determinadas dimensões da sua sexualidade a partir do diálogo com adultos, que lhes transmitem valores e normas. O artigo analisa conversas sobre sexualidade de adolescentes com seus pais, onde são articulados registros discursivos médicos e morais. A pesquisa é baseada em 46 entrevistas individuais com homens e mulheres de 15 a 19 anos de estratos socioeconômicos médios que residem em Trelew, cidade de noventa mil habitantes da Patagônia Argentina, e cursam o Ensino Médio. Para explicar as dinâmicas diferenciadas de diálogo entre adolescentes mulheres e homens, elaboramos as noções de controle parental da sexualidade feminina adolescente e onipresença material e discursiva do preservativo. Essas noções mostram como esses diálogos com adultos são atravessados por expectativas desiguais de gênero que, por sua vez, eles mesmos reforçam.

Palavras-chave: Adolescentes. Sexualidade. Diálogo com pais.
${ }^{*}$ Artículo inédito, elaborado con base en Jones (2008). Las y los adolescentes accedieron voluntariamente a ser entrevistados, manifestándolo por escrito, garantizándoles la confidencialidad y el anonimato de su participación.

${ }^{1}$ Consejo Nacional de Investigaciones Científicas y

Técnicas, Instituto de Investigaciones Gino Germani, Universidad de Buenos Aires. Castelli 25, 60 "25".CP 1031

Ciudad Autónoma de Buenos Aires (Argentina). jonesdaniel@speedy. com.ar 


\section{Introducción}

En las charlas de las mujeres y los varones adolescentes con adultos, y a través de algunos silencios, se transmiten valores y normas que se ponen en juego en sus opiniones y comportamientos sexuales. Este artículo analiza las conversaciones sobre sexualidad de adolescentes con sus padres y madres. Partimos de 46 entrevistas individuales a varones y mujeres de 15 a 19 años residentes en Trelew, una ciudad de noventa mil habitantes de la Patagonia argentina, pertenecientes a estratos socioeconómicos medios ${ }^{2}$ y que asisten a escuelas secundarias.

Este análisis permite explorar una parte significativa del complejo proceso de construcción de la sexualidad de adolescentes. Considerando el papel socializador de normas sexuales de padres y madres (Gagnon, 1990), es importante indagar no sólo las grandes formaciones que organizan la sexualidad (como la religión, la medicina o el sistema educativo), sino también cómo dichas fuerzas actúan por mediación de la "vida privada" en la educación de los hijos en la familia (Vance, 1989).

Luego de las amistades, para las mujeres entrevistadas la madre es su segunda interlocutora más frecuente en cuestiones de sexualidad, y para los varones es el padre y los padres (padre y madre). ${ }^{3}$ Cuando preguntamos con quiénes nunca hablan del tema, las mujeres primero mencionan a los padres -señalados por todas las que no habían indicado a la madre como interlocutora habitual- y luego el padre; en total, dos terceras partes de las entrevistadas no hablan nunca de sexualidad con su padre. Entre los varones, los docentes son los más mencionados como aquellos con quienes nunca hablan del tema, y luego los padres. ${ }^{4}$

En el primer apartado caracterizamos brevemente a Trelew, donde se criaron y residen las y los entrevistados, para situar localmente el proceso de construcción social de su sexualidad. A continuación analizamos de qué temas de sexualidad y cómo hablan con sus padres. En términos metodológicos, reconstruimos la interacción entre adultos y adolescentes tal como la presentan estos últimos.

\section{Trelew}

Trelew se encuentra en la provincia del Chubut, en la Patagonia argentina, donde la gran extensión geográfica y la dispersión de las localidades determina un importante grado de aislamiento periférico, por las distancias y costos para viajar a otras ciudades, especialmente las grandes urbes (como Buenos Aires, Rosario o Córdoba), todas a más de $1500 \mathrm{~km}$ de Trelew.

A su vez, otro rasgo local significativo es el menor peso de la Iglesia Católica en la vida pública de la provincia, en comparación con lo que sucede a nivel nacional $y$, sobre todo, en el Norte argentino. Esto puede vincularse a la temprana presencia de protestantes en la zona, con los colonos galeses en el siglo XIX, y la tardía presencia del catolicismo en el medio local, en comparación con el resto del país: hasta 1907 no hubo templo católico ni sacerdote en Trelew. El menor peso del catolicismo en Chubut se refleja, por ejemplo, en que fue la primera provincia argentina que eligió un gobernador no católico (en 1987) y en que la Iglesia Católica no tuvo un papel relevante durante la discusión de la ley provincial de salud sexual y reproductiva, a diferencia de lo sucedido a nivel nacional y en otras provincias. Esto ayuda a comprender la ausencia de discursos religiosos en las charlas entre adolescentes y sus padres, donde, con todo, aparecen otros valores tradicionales.
${ }^{2}$ Las y los entrevistados pertenecen a estratos medio-medio y mediobajo. En el artículo no los identificamos según su estrato porque no hallamos ninguna diferencia en los fenómenos analizados a partir de dicha dimensión. Para definir su estrato socioeconómico consideramos, primero el hecho de que están escolarizados en el nivel secundario diurno a la edad esperada para realizar cada curso y que ninguno trabaja ni busca empleo para sostenerse económicamente.

Segundo, tomamos el nivel educativo y la ocupación del padre y/o la madre con quien viven. Incluimos en el estrato medio-medio

a los adolescentes cuyo padre y/o madre tienen estudios secundarios completos (muy pocos tienen estudios universitarios) y ocupaciones de media o alta calificación: profesional contratado, personal jerárquico estatal o de empresas, docente de secundario, propietario de comercio. Incluimos en el estrato medio-bajo a aquellos cuyo padre $y / o$ madre tiene como máximo nivel educativo secundario incompleto y ocupaciones de baja calificación: operario fabril, trabajador de la construcción, peón de taxi, vendedor de comercio, jubilados de estas ocupaciones. Indagamos si existían diferencias en los diálogos sobre sexualidad de adolescentes con sus padres, en cuanto a temáticas y valores, según el nivel educativo o profesiones de estos adultos, sin hallar correlaciones relevantes. 
${ }^{3}$ A fines de facilitar la lectura, utilizamos la expresión "padres" para referirnos a padres y madres cuando la distinción entre ambos no resulte analíticamente relevante. En el caso de aludir sólo a padres varones, así lo indicamos cuando sea preciso. Seguimos un criterio semejante con la expresión "adultos".

${ }^{4}$ Sin embargo, tanto varones como mujeres resaltan el papel intermedio que puede cumplir un docente, en relación a padres y pares, para hablar sobre sexualidad, al infundir la seguridad y confianza que dan la experiencia y madurez de un adulto, sin la vergüenza que genera tratarlo con los padres. Sobre las diferencias entre varones y mujeres al hablar de sexualidad con docentes, ver Jones (2008)

${ }^{5}$ Las palabras entrecomilladas son términos nativos. Aunque usan "enfermedades" y "contagio", para las situaciones a las que refieren los adecuados serían "Infecciones de Transmisión Sexual" (ITS) y "transmisión".

${ }^{6}$ Los nombres han sido cambiados para preservar el anonimato.

${ }^{7}$ Nos referimos a la primera relación sexual coital.

${ }^{8}$ Una expresión vulgar sobre la disposición corporal femenina para tener relaciones sexuales, enfatizando la pasividad de la mujer y que es penetrada.

\section{El control parental de la sexualidad femenina adolescente}

Los diálogos sobre sexualidad entre las mujeres y sus padres se centran en los consejos sobre "cuidarse" de embarazos y "enfermedades" ${ }^{y}$, en menor medida, en las experiencias sexuales de estas jóvenes. En las charlas el discurso de los padres articula registros médicos y morales. Con registro médico nos referimos a sugerencias e informaciones que presentan como fuente y base de autoridad, tácita o explícitamente, un saber biomédico. Por registro moral entendemos "un conjunto de valores y de reglas de acción que se proponen a los individuos y a los grupos por medio de aparatos prescriptivos diversos, como pueden serlo la familia, las instituciones educativas, las iglesias, etc." (Foucault, 2003, p. 26). Estos valores y reglas conforman un código moral que se transmite de manera difusa y que, "lejos de formar un conjunto sistemático, constituyen un juego complejo de elementos que se compensan, se corrigen, se anulan en ciertos puntos, permitiendo así compromisos o escapatorias" (Foucault, 2003, p.26).

Los testimonios de Meibel, Maite y Nachi ${ }^{6}$ muestran cómo se articulan ambos registros en los consejos de adultos que, además de procurar la prevención de embarazos y enfermedades, brindan orientaciones morales para la actividad sexual de sus hijas:
"Informante: En un tiempo mi mamá me hablaba de esas cosas [de sexualidad]. Me prevenía.
Entrevistadora: ¿Qué te decía tu mamá? ¿De qué hablabas con ella? I: De las maneras anticonceptivas para cuidarte, del hacerlo por amor... $Y$ después, de no regalarte al primero que se te cruza... El hecho de no tener sexo enseguida... Como que lo hacés y te abriste de gambas [piernas] y nada más". (Meibel, 17 años, se inició sexualmente ${ }^{7}$ a los 15 con un novio)

Meibel señala que su madre la "prevenía" en cuestiones de sexualidad, un término que connota tanto recomendación como advertencia sobre qué hacer y qué no, y enumera en pie de igualdad dos consejos en distintos registros: las "maneras anticonceptivas" y el "hacerlo por amor". Luego agrega tres frases que permiten reconstruir la orientación moral brindada por su madre: "no regalarte al primero que se te cruza", "no tener sexo enseguida" y no "abrirte de gambas y nada más", consejos que apuntan a que Meibel evite dos comportamientos. Por un lado, que no tenga relaciones sexuales con parejas ocasionales, pues las expresiones "el primero que se te cruza" y "enseguida" refieren a la ausencia de un vínculo socioafectivo previo, estable o duradero. Por otro lado, que evite relaciones motivadas sólo por las ganas, en oposición a "hacerlo por amor". Estos consejos distinguen comportamientos legítimos e ilegítimos, algo que refuerzan las expresiones utilizadas. "Regalarte al primero que se te cruza" implica otorgarse tan poco valor a sí misma como mujer que, siguiendo la metáfora comercial, se entregaría a un hombre que no paga ningún precio por tener relaciones sexuales con ella, como, por ejemplo, estar de novios (de ahí que la frase aluda a parejas ocasionales). Estrechamente ligado, "abrirte de gambas ${ }^{8}$ y nada más" significa aceptar tener relaciones sin que haya una dimensión que exceda al mero interés sexual y, por ende, justifique ese encuentro. La distinción respecto de "hacerlo por amor" nos indica que, ante la mirada de su madre, este sentimiento legitimaría las relaciones sexuales, y no así el deseo o placer erótico de Meibel. Esta justificación de las relaciones sexuales de mujeres jóvenes mediante el discurso del amor es un fenómeno ampliamente registrado 
en América latina (Sosa, 2004; Amuchástegui, 2001; Cáceres, 2000; Pantelides, Geldstein, Infesta Domínguez, 1995).

En las charlas entre Maite y su padre (ginecólogo y obstetra), él también articula ambos registros al explicarle los métodos para "cuidarse" y destacar que el mejor es la abstinencia sexual, una observación cierta en sentido estricto pero que implica no tener relaciones:

\footnotetext{
“I: A mí mis padres me explicaron todos los métodos y me dijeron que la abstinencia era el mejor método. O sea, yo tengo 17 años y todavía no me siento lista. Y tampoco tuve nunca una pareja estable más de dos meses. [...]

E: Y con tu papá por ejemplo, ¿qué hablás?

I: Los métodos de cómo cuidarse, todo eso. [...] Mi papá me dio una charla más médico. Me dijo con los métodos cómo cuidarte, que mantenga pareja estable y eso". (Maite, 17 años, aún no se inició sexualmente)
}

Maite explica que no ha tenido relaciones sexuales porque no se siente preparada y nunca tuvo una pareja estable más de dos meses, lo que indica que considera a este tipo de vínculo y esa duración condiciones necesarias para tener relaciones. El discurso de su padre combina los registros médico y moral: dando "una charla más [como] médico" (apelando a la autoridad que brinda ese saber), le recomienda la abstinencia como el mejor método para cuidarse y conservar una pareja estable (lo que para una adolescente es sinónimo de noviazgo). Ambos consejos parecerían contradictorios: ¿para qué mantener una pareja si precisamente su continuidad temporal aumentaría las posibilidades de que Maite tenga relaciones? Sin embargo, estos consejos pueden articularse en una misma orientación normativa presente en el discurso de estos adultos hacia sus hijas: "en lo posible no tengas relaciones sexuales durante tu adolescencia pero, en caso de tenerlas, que sea con un novio, por amor y utilizando algún método de prevención del embarazo y las enfermedades".

También articulan ambos registros los padres de Nachi, quien relata cómo su madre habla de sexualidad con sus hermanos varones (de 17 y 18 años) y cómo su padre charla con ella:

\footnotetext{
"Mi mamá siempre habla con mis hermanos. Les dice que cuando ellos tengan una relación sexual se cuiden porque pueden traer enfermedades o pueden dejar embarazada a una chica y capaz que ellos no quieren dejarla embarazada. Cuando ellas... cuando ellos quieran tener un hijo que ahí sí no se pongan condón. [...] Mi papá siempre me dice que si en algún momento yo estoy con un novio "y sienten ganas", pero porque lo quiero... Que me cuide, que tenga en cuenta todas las enfermedades que me puedo traer, y no quedar embarazada". (Nachi, 15 años, aún no se inició sexualmente)
}

El punto de partida común es la presunción de heterosexualidad de estos adultos (una constante registrada en nuestro estudio), mediante consejos que colocan como pareja sexual a una persona del género opuesto o el énfasis en el uso de anticonceptivos. Dichos consejos operan en la institución de la heterosexualidad, en el marco de la matriz heterosexual: "La institución de una heterosexualidad obligatoria y naturalizada requiere y reglamenta al género como una relación binaria en que el término masculino se diferencia del femenino, y esta diferenciación se logra por medio de las prácticas del deseo heterosexual" (Butler, 2001, p. 56). Si bien ambos diálogos comparten esta presunción y giran sobre el mismo tema, hay diferencias significativas. Con Nachi, su padre refiere elípticamente a las relaciones sexuales (sin mencionarlas) y supone y refuerza con quién y por qué motivo debería tenerlas: con un novio y porque ella lo quiere, es decir, sus "ganas" (su deseo sexual) deben acompañarse de, o subordinarse al, amor. Además, no le señala métodos de prevención, sino sólo que se "cuide". En cambio, con los hermanos de Nachi, su madre habla de una "chica" como compañera sexual, sin especificar el tipo de pareja, no les indica los motivos para tener relaciones y les señala el preservativo. Estas diferencias muestran cómo los consejos de adultos establecen requisitos más estrictos para la actividad sexual de sus hijas: el compañero sexual debería ser un novio y la motivación el amor. Como sostienen Heilborn, Cabral y Bozon (2006, p.211): “En la construcción social del género 
femenino hay una subordinación del sexo a la afectividad, designada como perspectiva relacional referente a la sexualidad $y$, en contrapartida, la sexualidad en los hombres es socialmente moldeada como portadora de sentido en sí misma". Por otra parte, el no señalar métodos específicos de prevención revelaría un carácter más elíptico de las recomendaciones de adultos a sus hijas mujeres, como destacan otros estudios: entre jóvenes escolarizadas de nivel secundario en Lima (Perú), "la prescripción parental central a las chicas es un omnipresente 'cuídate', genérico y tangencial" (Cáceres, 2000, p.38), mientras que en Santiago de Chile, "el discurso para las hijas adolescentes se centra fuertemente en el cuidado, en general, sin oferta de medios concretos, sin referencia a ningún método anticonceptivo" (Valdés, 2005, p.334).

El relato Nachi sintetiza cómo varían los consejos sobre sexualidad según se trate de un hijo o una hija, reforzando códigos morales diferenciados. Estos códigos retoman escenarios culturales tradicionales en términos de género. Con tradicional designamos a una concepción jerárquica y asimétrica de las relaciones de género, así como a normatividades para la actividad sexual rígidamente diferenciadas para varones y mujeres. En estas charlas padres y madres retoman imágenes de género donde predominan el amor-pasión como característica masculina y el amor romántico como definitorio de la sexualidad femenina (Szasz, 2004). El primero implica una conexión intensa entre el amor y la atracción sexual, mientras que en el amor romántico los afectos tienden a predominar sobre el ardor sexual (Giddens, 1995). En Argentina, las creencias del amor romántico se han difundido a través de diversos medios y formatos culturales orientados hacia las mujeres (folletín, radioteatro, teleteatro), de inicios del siglo XX al presente (Torrado, 2003), actuando como relato legitimante de la sexualidad femenina.

La otra cuestión que sobresale en estas conversaciones es la asociación constante entre actividad sexual y reproducción, mediante advertencias sobre el riesgo de quedar embarazadas. Algunos adultos presentan a sus hijas adolescentes un encadenamiento automático entre comienzo de las relaciones sexuales, embarazo, maternidad (no mencionan la opción de abortar) y derrumbe del proyecto de vida. Esta idea retoma una extendida percepción en América latina de que el embarazo en la adolescencia es esencialmente un problema y perturba el desarrollo del curso de vida, percepción compartida por los medios de comunicación y los servicios educativos y sanitarios (Knauth et al., 2006; Villa, 2007). El proyecto de vida de estas chicas escolarizadas supone asistir a la universidad, para lo que consideran condición necesaria no tener que criar un hijo. Como registra una investigación de adolescentes escolarizados en la ciudad de Buenos Aires, "la posibilidad de embarazos puede ser experimentada con temor [...] cuando éstos son percibidos como una ruptura de la autonomía individual y de la continuidad en el estudio" (Villa, 2007, p.102). Para acceder a ciertas carreras universitarias estas jóvenes deben emigrar a ciudades lejanas con mayor oferta educativa, para lo que reconocen un obstáculo en el embarazo y la maternidad. En este entramado de expectativas y asociaciones, algunos adultos intentan disuadir a sus hijas de tener relaciones en la adolescencia (sugiriéndoles que las posterguen), a través de recomendaciones preventivas en un registro médico. Un ejemplo es el consejo de abstinencia del padre de Maite, a la sazón de profesión médico, que delinea la sexualidad que considera legítima para su hija mediante argumentos presuntamente científicos. La articulación de registros morales y médicos en estos consejos puede interpretarse, siguiendo a Foucault (2000), como parte de un dispositivo de control social sobre la sexualidad que la medicina a menudo legitima, cuando no ejerce directamente. Desde el siglo XVIII, progresivamente "la iniciativa para juzgar la sexualidad pasó de las iglesias a los encargados de la higiene social y mental, sobre todo de profesión médica. Ésta ha sido una revolución inconclusa en el sentido de que los asuntos morales y médicos siguen estando inextricablemente vinculados" (Weeks, 1998, p.94).

Otras charlas de las adolescentes con sus madres se centran en sus relaciones sexuales:

"I: Mi mamá sabe que tengo relaciones, de eso nunca hablé mucho con ella.

E: ¿Qué te decía tu mamá?

I: Cuando le conté que tenía relaciones no le gustó demasiado. Creo que esperaba que no las tuviera.

E: ¿Y vos qué pensás? 
I: iQué pensamiento retrógrado! La verdad es que me molestó bastante porque yo fui a contárselo, me parecía que era algo que me gustaría compartir. De hecho me gustaría que mis hijos me lo contaran. Y esperaba que le pareciera mejor. Tampoco que me haga una fiesta. E: ¿Qué te dijo?

I: Me dijo: "Yo no quería, yo no esperaba que vos tuvieras relaciones ya. ¿Se cuidan?". Yo se lo quería contar y esperaba que [diga]: "Qué bueno que me contaste. Sabés que a mí... Vos sabés que...". Y bueno, pero nada de eso pasó.

E: ¿Y no hablaron más del tema?

I: No. Ahora estoy yendo a la doctora para ver si tomo

anticonceptivos". (Karina, 17 años, se inició sexualmente a los 16)

Karina le contó a la madre que tenía relaciones sexuales con su novio, con quien fue su primera vez. Esperaba que se alegrara por habérselo contado por voluntad propia y que, en consecuencia, la madre compartiera alguna experiencia. Nada de eso sucedió: por el contrario, la madre le expresó su disgusto porque tuviese relaciones y sólo le preguntó si se cuidaban, una reacción que contiene los dos registros mencionados. Por un lado, en la frase "Yo no quería, yo no esperaba que vos tuvieras relaciones ya", el "ya" refiere a la edad de Karina y expresa una regla moral que considera precoces y, por lo tanto, inadecuadas las relaciones sexuales a esta edad. Por otro lado, la pregunta " ¿se cuidan?" alude a si usan algún método preventivo cuando mantienen relaciones, inscribiéndose en un registro discursivo médico. Que la única e inmediata consulta de su madre sea sobre los cuidados, a la que Karina responde yendo a una médica por anticonceptivos orales, indica la dificultad de algunas madres (y padres) para hablar de sexualidad con las adolescentes más allá de la prevención del embarazo. La referencia a las píldoras en las charlas con sus madres se vincula a un escenario cultural sobre la sexualidad femenina adolescente donde ocupa un lugar central el temor al embarazo. La interacción relatada por Karina muestra un choque de expectativas que influye en la posibilidad de otros diálogos con sus padres: la esperanza de que la madre se alegre por la confianza depositada al contarle que tenía relaciones y comparta su propia experiencia choca con la recriminación de ésta, lo que contribuye a que no vuelvan a hablar de relaciones sexuales y, además, a que Karina no comente nada a su padre.

A modo de síntesis construimos la categoría control parental de la sexualidad femenina adolescente para dar cuenta de los contenidos y dinámicas de los diálogos sobre sexualidad de las adolescentes con sus padres. Este control consiste en una regulación y sanción de la actividad sexual de las adolescentes a través de consejos, restricciones y recriminaciones que, articulando registros médicos y morales, establecen orientaciones normativas sobre comportamientos legítimos e ilegítimos. ${ }^{9}$ Dichas orientaciones también guían a las jóvenes acerca de qué pueden hablar con ellos y sobre qué no, lo que nos lleva a los silencios.

Las entrevistadas consideran que los silencios sobre sexualidad de los adultos ante las hijas adolescentes se orientan a negar su actividad sexual, una negación que podemos interpretar como ignorancia y como prohibición. La negación como ignorancia implica que cuando las mujeres comienzan con inquietudes sobre sexualidad y, sobre todo, a tener relaciones sexuales, sus padres no les hablan al respecto porque supuestamente desconocen estas vivencias. Decimos supuestamente porque dicho desconocimiento sería una mezcla de no saber que sus hijas tienen relaciones y no querer que las tengan durante la adolescencia:
9 Para esta definición nos inspiramos en las nociones de vigilancia y sanción de Foucault (1989), evitando oponer "control" y "sexualidad", como si ésta fuese una naturaleza que el poder intentaría reprimir (Foucault, 2000, p.129). 
“E: ¿Y con quién nunca hablaste de sexualidad?

I: Con mi mamá.

E: ¿Por qué?

I: Me da vergüenza.

E: ¿Y ella nunca te habló?

I: No. Pienso que también le debe preocupar que... "Mirá, ya está creciendo y...".

E: ¿Y con tu papá?

I: (riéndose) No, él no. Él siempre cree que soy una nena, piensa que soy una nena. Dice: "Mi

nena" y nada más... ya no quiere que crezca". (Belén, 19 años, se inició sexualmente a los 19)

Mientras que Belén sospecha que su silenciosa madre debe estar preocupada por su sexualidad, el padre ejemplifica la mezcla entre no saber y no querer que su hija tenga actividad sexual: no hablaría con Belén del tema tanto porque cree que es una "nena" y como tal no tendría relaciones, como porque no quiere que su hija crezca y efectivamente las tenga. Otros testimonios reflejan dicha articulación entre la negación como ignorancia y como prohibición: los adultos ignoran todo el tiempo posible que sus hijas tienen relaciones hasta que, cuando lo sospechan fuertemente o se enteran, comienzan las recriminaciones y prohibiciones. En estas situaciones también se da el control parental de la sexualidad femenina adolescente, ya no bajo la forma de consejos sino a través de vigilancia y límites a sus actividades:

“E: ¿Con quiénes es poco frecuente hablar de sexualidad?

I: Y... con los padres generalmente.

E: ¿Y a qué atribuís que no se habla?

I: Muchos padres viven la sexualidad de los hijos como algo que es de ellos, o como algo que todavía no existe para algunos o que no debería existir para otros. Entonces, ante la posibilidad de encontrar una respuesta negativa, es preferible no contarlo. Ésa es la actitud que se toma generalmente. Porque algunos padres se desilusionan o después están controlando todo el tiempo, y el chico... generalmente en el caso de las mujeres, si vas a salir a bailar, ya es toda una historia, porque atrás de eso imaginan un montón de cosas. [...] Como que pueden esperar cualquier cosa de vos.

E: ¿Más en las mujeres que en los varones o es igual?

I: En general más en las mujeres que en los varones. Los padres de los varones suelen ser más piolas, lo tienen más aceptado y algunos hasta prefieren abrirles las puertas de la casa con tal de que no se vayan a otro lado. En las mujeres se vive como más escondido eso". (Lucía, 17 años)

Para Lucía las chicas prefieren no contar de sus relaciones sexuales a sus padres por miedo a una reacción negativa, como la desilusión o el control. Como ilustra la madre de Karina, la posibilidad de dicha desilusión no es una fantasía de las jóvenes. La noticia de que una adolescente ya tiene relaciones la coloca bajo sospecha y activa la vigilancia de sus padres, por ejemplo, cuando sale a bailar. Esta dinámica supone una actitud diferente de los adultos según se trate de hijos o hijas, que ayuda a entender por qué algunas mujeres no hablan con los padres de su actividad sexual. Mientras que frente a los hijos varones los adultos serían más abiertos, llegando a ofrecer la casa familiar para tener relaciones, una chica lo viviría más clandestinamente, por temor a que si se enteran sus padres empiecen los controles a sus rutinas, una diferencia entre géneros también registrada en adolescentes de Buenos Aires (Villa, 2007) y Cuernavaca (México) (Sosa, 2004). Dichas dinámicas reflejan la productividad del poder (Foucault, 2000), pues este control no solamente restringe, sino que está en el corazón mismo de la producción de ciertos comportamientos sexuales, como profundizamos a continuación.

\section{La omnipresencia material y discursiva del preservativo}

Los diálogos sobre sexualidad de los varones con su padre y/o madre se centran en el preservativo $y$, en menor medida, en sus experiencias sexuales. Los primeros presentan una secuencia común: 
el padre o la madre aconseja al adolescente sobre el uso de preservativos y acompaña el consejo entregándoselos o dándole dinero explícitamente destinado a su compra.

“E: ¿Y cómo es que vos tenías forros [preservativos]? ¿Siempre andás con forros?

I: Sí, porque mi viejo [padre] me compró.

E: ¿Cuando empezaste a andar con esta chica o antes?

I: Antes, antes. "Por las dudas", me dijo. Porque ya me había dado indicaciones de un montón de cosas, después me los compró y cuando tuve la posibilidad los usé". (Martín, 18 años, se inició sexualmente a los 15)

Muchos varones mencionan recibir preservativos o dinero para comprarlos: generalmente el padre se los facilita con bastante antelación a su eventual uso, desde el momento en que comienzan a salir a bailar a las discotecas, a los 14 años. Esta entrega tiene dos tipos de efectos: uno práctico, porque los jóvenes disponen de preservativos para cuando se presente la ocasión de utilizarlos (como hicieron varios en su primera vez y/o encuentros posteriores); y otro simbólico, pues proporcionar profilácticos refuerza el consejo con una dimensión material. Cuando termina la charla el adolescente cuenta con preservativos e información sobre cómo usarlos, lo que contrasta con la experiencia de algunas chicas, que sólo reciben de sus padres un genérico "cuidate", sin recomendarles o facilitarles métodos concretos. Sin embargo, los efectos simbólicos de esta secuencia no acaban ahí: el suministro de profilácticos legitima desde y ante los padres la posibilidad de que su hijo mantenga relaciones sexuales. ${ }^{10}$ La orientación normativa rezaría: "podés tener relaciones sexuales durante tu adolescencia siempre y cuando uses preservativo". Esto significa que dichos consejos no se dan en un registro exclusivamente médico. A diferencia de las charlas con las hijas, en aquellas con varones no aparecen requisitos sobre el tipo de vínculo con la compañera sexual y la motivación para tener relaciones, pero igualmente se pone en juego un mensaje moral: presuponen que estos adolescentes ya tienen relaciones o las tendrán en breve y, por ende, las aprueban. La orientación normativa se da en un sentido inverso al control parental de la sexualidad femenina adolescente, que indica que en lo posible las mujeres no deberían tener relaciones sexuales en su adolescencia.

Las charlas sobre el preservativo en ocasiones se enlazan con las referidas a sus experiencias sexuales:

“E: ¿Y alguna vez tus papás te dijeron algo sobre el tema de las minas [chicas]?

I: Siempre me dijeron que tenía que tener el famoso preservativo en la billetera. Porque en un boliche [discoteca] nunca sabés qué pasa. Y por más que vos sepas que con una mina estás hace un mes, no sabés si tiene algo, entonces por las dudas a mí siempre me dijeron: "Vos siempre llevalo, es mejor prevenir".

$\mathrm{E}:$ ¿Y eso te lo dijeron desde qué edad?

I: Desde los 14. Es que yo a los 14 ya empecé a estar [de novio] con una piba. [...]

E: ¿Y cómo era el tema? ¿Ellos te compraban el preservativo?

I: No, me daban plata. Si necesitaba plata para preservativos siempre iba, pedía y me daban. [...]

E: ¿Y cuando empezaste a tener relaciones le comentaste algo a tus viejos?
${ }^{10}$ Algo semejante sucede con el hecho de que la madre acompañe a una hija a la ginecóloga para que le prescriba píldoras anticonceptivas y/o se las compre, relatado por dos entrevistadas. Ninguna menciona haber recibido preservativos de su madre o padre. 
I: Yo les dije: "Bueno, hoy les tengo que decir algo". Los senté a los dos y les dije: "Ya tuve mi primera relación, me cuidé, la pasé re bien". Se cagaban de risa. Así que todo bien, estaban contentos de que me haya cuidado. No me decían nada referido a la edad". (Emiliano, 18 años, se inició sexualmente a los 14)

Al igual que Karina, Emiliano describe cómo fue contar a sus padres que había tenido su primera vez. El contraste entre ambas vivencias ilumina diferencias significativas entre mujeres y varones en estos diálogos. Mientras que Emiliano cuenta su iniciación a su padre y madre juntos, señalándoles que se había cuidado y que la había pasado muy bien, Karina se dirige sólo a su madre, la referencia a los cuidados es por una pregunta de ésta y no menciona haberlo disfrutado. Cabe preguntarse qué posibilidad tenía Karina de compartir con el padre esta experiencia, si consideramos que dos terceras partes de las mujeres entrevistadas no hablan con su padre de ningún tema de sexualidad y quienes lo hacen se centran en los cuidados. En contraposición, varios varones destacan una actitud complementaria del padre y la madre, quienes demuestran interés y predisposición para hablar con ellos de sexualidad, juntos o por separado. La mención de Emiliano de haber disfrutado del encuentro sexual contrasta con el silencio de Karina al respecto, algo que se enmarca en un patrón común de los relatos femeninos: la ausencia de referencias al placer sexual en las charlas con sus padres. A su vez, que Emiliano señale espontáneamente haberse cuidado puede ser producto de la insistencia previa de sus padres sobre el preservativo. En los testimonios aparecen otras dos diferencias. Por una parte, la reacción negativa de la madre ante el relato de Karina contrasta con la alegría de los padres de Emiliano, lo que él atribuye a que haya utilizado preservativo. Por otra parte, la ausencia de recriminaciones por su edad al varón, que percibe el propio Emiliano, se contrapone con el reproche de la madre a Karina al decirle que "no esperaba que tuvieras relaciones ya". Como otro ejemplo de las expectativas diferenciadas de los padres respecto a la actividad sexual de hijos e hijas, recordemos que Karina tuvo su primera vez a los 16 años, mientras que Emiliano la tuvo a los 14. En resumen, desde el momento en que los padres aconsejan a Emiliano sobre el preservativo y le dan dinero para comprarlo, admiten la posibilidad de que tenga relaciones en breve $y$, consecuentes con dicha perspectiva, se alegran porque su hijo se cuidó al debutar. Las diferencias entre ambas interacciones son producto de, y refuerzan, expectativas de género y agencias desiguales para los participantes de estos diálogos con adultos.

A modo de síntesis construimos la categoría omnipresencia material y discursiva del preservativo para dar cuenta de los contenidos y dinámicas de las charlas sobre sexualidad de los adolescentes varones con su padre y/o madre. En esta interacción el preservativo ocupa un lugar central no sólo mediante consejos sobre su uso, sino también a través de la entrega de profilácticos o dinero para comprarlos. Estas acciones traen aparejado un reconocimiento simbólico de las relaciones sexuales de los varones desde y ante los padres, en un sentido opuesto al control parental de la sexualidad femenina adolescente, que desalienta, condiciona o recrimina la actividad sexual de las mujeres. Dicho reconocimiento adulto, diferencial según el género de la o el adolescente, actuaría como horizonte regulativo de sus comportamientos, incitando de algún modo a los varones a tener contactos sexuales, lo que refleja una dimensión productiva del poder. Este contraste reproduce un doble patrón de moral sexual que viene de larga data en Argentina (Torrado, 2003, p.129-35) y en América latina en general:

Este patrón se funda en la comprensión de una diferencia fundamental en las naturalezas sexuales de hombres y mujeres, [...] [en la que] el tratamiento cultural de la sexualidad femenina está claramente dirigido para el control y la limitación. [...] El tratamiento de la sexualidad masculina, al contrario, debe ser la incitación, y un discurso casi constante sobre asuntos sexuales, [...] una continua y explícita educación sexual ofrecida por hombres más viejos a los jóvenes.

\section{Reflexiones finales}

En este artículo analizamos los diálogos y silencios de adolescentes con sus padres como parte del proceso de construcción social de su sexualidad. Vimos cómo los consejos de adultos establecen 
orientaciones normativas sobre la actividad sexual que pueden sintetizarse en dos fórmulas. Para las mujeres: "en lo posible no tengas relaciones sexuales durante tu adolescencia pero, en caso de tenerlas, que sea con un novio, por amor y utilizando algún método de prevención del embarazo y las enfermedades"; para los varones: "podés tener relaciones sexuales durante tu adolescencia siempre y cuando uses preservativo".

¿Qué fenómenos sociales permiten entender la presencia de estos consejos en las conversaciones entre adolescentes y sus padres? 1) El reconocimiento de los adultos de que una proporción importante de adolescentes tiene relaciones sexuales, más allá de su valoración al respecto; 2) la extendida percepción del embarazo en la adolescencia como un problema que afecta al proyecto de vida de las mujeres; 3) la visibilidad de la epidemia del VIH/Sida a través de los medios de comunicación; y 4) el debate público sobre salud sexual y reproductiva en Argentina, desde la década de 1990.

Sin embargo, en estos consejos difieren los mensajes para varones y mujeres. Las recomendaciones de padres refuerzan una jerarquía de comportamientos para las chicas que coloca en primer lugar a la abstinencia sexual durante la adolescencia y sólo en segundo lugar a las relaciones protegidas. A su vez, instauran requisitos sobre con quién y por qué motivo deberían tener estas relaciones (con un novio y por amor), que si se cumplen legitimarían la actividad sexual de las adolescentes ante la mirada adulta. En cambio, para los varones no especifican el tipo de vínculo con la compañera sexual, ni la motivación para tener relaciones, indicando como único requisito el preservativo. Amén de presuponer la heterosexualidad de sus interlocutores, estos consejos refuerzan códigos morales desiguales. Por eso propusimos las categorías control parental de la sexualidad femenina adolescente y omnipresencia material y discursiva del preservativo para dar cuenta de las dinámicas de diálogo entre adultos e hijas y adultos e hijos, respectivamente. El control parental no sólo se da a través de consejos, sino también mediante la negación de la actividad sexual de las chicas, en los sentidos de ignorancia y prohibición. Los adultos ignoran todo el tiempo posible que sus hijas tienen relaciones sexuales, manteniendo silencio al respecto, y cuando se enteran comienzan las recriminaciones, controles y prohibiciones. En cambio, la omnipresencia del preservativo en la interacción entre adultos e hijos varones pone en juego otro mensaje moral: los padres suponen que estos adolescentes tienen o tendrán en breve relaciones sexuales y tácitamente las aprueban al facilitarles preservativos y aconsejarles su uso. Estas acciones implican un reconocimiento de la actividad sexual de los varones desde los progenitores, en un sentido inverso al control parental que condiciona o desalienta las relaciones sexuales de las mujeres.

En las charlas con las chicas es nodal la asociación entre actividad sexual y reproducción, al enfatizar la posibilidad del embarazo y la maternidad si tienen relaciones. Esto permite que algunos padres presenten a la abstinencia en la adolescencia como una alternativa razonable y da cuenta de una inquietud prioritaria por el embarazo que se refleja en otro fenómeno: algunas madres que se enteran de que sus hijas tienen relaciones les aconsejan cuidarse a través de píldoras anticonceptivas. Si por un lado resulta un avance frente al silencio de muchos padres, por el otro deja a estas chicas expuestas al VIH y otras ITS de no complementarlas con el preservativo (como lo hacen sólo algunas de ellas). La diferencia entre este consejo y aquel dado a varones sobre el preservativo, sumado a que ninguna chica ha recibido profilácticos de sus padres, plantea dos interrogantes. Primero, si esta insistencia en diferentes métodos tiene que ver con quién puede decidir usarlos. Segundo, si la recomendación de pastillas a las chicas descansa en que sus madres consideran lejana la posibilidad de que contraigan una ITS, mientras que, simultáneamente, evalúan que las peores consecuencias de no usar anticonceptivos recaerán sobre ellas.

Estas diferencias en las recomendaciones recibidas se reflejan en aquello que más les preocupa de tener relaciones sexuales. La principal preocupación de los varones es que el preservativo falle, porque esté pinchado, se rompa o simplemente falle al utilizarlo. La consecuencia que más les inquieta es que su compañera sexual quede embarazada y, en menor medida, "contagiarse" una enfermedad. La segunda preocupación más mencionada se centra directamente en contraer el VIH. Entre las mujeres, el hecho de quedar embarazada es la principal preocupación, le sigue el contraer una enfermedad, mientras que sólo una teme que falle el preservativo. Estas preocupaciones dan cuenta de cómo las y los adolescentes construyen dimensiones de su sexualidad a partir de diálogos atravesados por 
expectativas de género desiguales. Para los varones la falla del preservativo constituye en sí el objeto de su preocupación, pues la omnipresencia material y discursiva del preservativo en las charlas con sus padres influye para que consideren que todo aquello que suceda con éste en la interacción sexual es su responsabilidad. El varón será el encargado de que el preservativo funcione efectivamente, ya que es quien usa dicho método y habitualmente lo provee. Si el preservativo es su responsabilidad y el único método de prevención que utilizan con su pareja (como declaran varios), su falla implica que el varón también sería el responsable si contrae alguna enfermedad o deja embarazada a su compañera. Que para las mujeres la principal preocupación sea el embarazo refleja cuán fuerte es la asociación entre actividad sexual y reproducción para la sexualidad femenina. En esta preocupación opera la idea, transmitida por sus padres, de que el embarazo y la maternidad en la adolescencia derrumbarían su proyecto de vida, particularmente los estudios universitarios.

En síntesis, procuramos destacar correspondencias significativas entre los consejos sobre sexualidad de adultos a adolescentes y sus preocupaciones. En los varones, mediante la centralidad del preservativo, tanto en la interacción entre padres e hijos como en los temores de los adolescentes de que falle. En las mujeres, a través de la asociación entre actividad sexual y reproducción, tanto en las recomendaciones de padres como en la preocupación de las chicas de quedar embarazadas.

Aunque estos y estas adolescentes escuchan a los adultos y valoran sus consejos, en ocasiones sus comportamientos van en otra dirección, como reflejan aquellas chicas que tuvieron relaciones a pesar de la prescripción parental de abstinencia durante la adolescencia, y decidieron no compartirlo con sus padres para evitar recriminaciones. Esta resistencia silenciosa muestra las dificultades que enfrentan los intentos de control sobre la actividad sexual de las chicas.

\section{Referencias}

AMUCHÁSTEGUI, A. Virginidad e iniciación sexual en México: experiencias y significados. México: EDAMEX y Population Council, 2001.

BUTLER, J. El género en disputa: el feminismo y la subversión de la identidad. México: Paidós, 2001.

CÁCERES, C. La (re)configuración del universo sexual: cultura(s) sexual(es) y salud sexual entre los jóvenes de Lima a vuelta del milenio. Lima: UPCH y REDESS Jóvenes, 2000.

FOUCAULT, M. La historia de la sexualidad II: el uso de los placeres. Buenos Aires: Siglo XXI, 2003.

. La historia de la sexualidad I: la voluntad de saber. México: Siglo XXI, 2000.

Vigilar y castigar: nacimiento de la prisión. Buenos Aires: Siglo Veintiuno, 1989.

GAGNON, J. The explicit and implicit use of the scripting perspective in sex research. Annu. Rev. Sex Res., n.1, p.1-43, 1990.

GIDDENS, A. La transformación de la intimidad: sexualidad, amor y erotismo en las sociedades modernas. Madrid: Cátedra, 1995.

HEILBORN, M.L.; CABRAL, C.; BOZON, M. Valores sobre sexualidade e elenco de práticas: tensões entre modernização diferencial e lógicas tradicionais. In: HEILBORN, M.L. et al. (Orgs.). O aprendizado da sexualidade: reprodução e trajetórias sociais de jovens brasileiros. Río de Janeiro: Garamond, 2006. p.207-66.

JONES, D. Sexualidad y adolescentes: prácticas y significados relativos a la sexualidad de adolescentes residentes en Trelew (Chubut). 2008. Tesis (Doctoral) - Facultad de Ciencias Sociales, Universidad de Buenos Aires, Buenos Aires. 2008. 
KNAUTH, D. et al. As trajetórias afetivo-sexuais: encontros, uniões e separação. In: HEILBORN, M. L. et al. (Orgs.). O aprendizado da sexualidade: reprodução e trajetórias sociais de jovens brasileiros. Río de Janeiro: Garamond, 2006. p.267-307.

PANTELIDES, E.; GELDSTEIN, R.; INFESTA DOMÍNGUEZ, G. Imágenes de género y conducta reproductiva en la adolescencia. Buenos Aires: CENEP, 1995.

SOSA, I. Significados de la salud y la sexualidad en jóvenes: estudio de caso en dos escuelas públicas en Cuernavaca. 2004. Tesis (Maestría) - Centro Regional de Investigaciones Multidisciplinarias, Universidad Nacional Autónoma de México, México. 2004.

SZASZ, I. El discurso de las ciencias sociales sobre las sexualidades. In: CÁCERES, C. et al. (Eds.). Ciudadanía sexual en América Latina: abriendo el debate. Lima: Universidad Peruana Cayetano Heredia, 2004. p.65-75.

TORRADO, S. Historia de la familia en la Argentina moderna (1870-2000). Buenos Aires: Ediciones de la Flor, 2003.

VALDÉS, T. Socialização em sexualidade no Chile: adolescentes de camadas populares urbanas. In: HEILBORN, M.L.; DUARTE, L.F.O.; PEI, C. (Orgs.). Sexualidade, família e ethos religioso. Río de Janeiro: Garamond, 2005. p.315-42.

VANCE, C. El placer y el peligro: hacia una política de la sexualidad. In: (Comp.). Placer y peligro: explorando la sexualidad femenina. Madrid: Hablan las Mujeres, 1989. p.9-49.

VILLA, A. Cuerpo, sexualidad y socialización: intervenciones e investigaciones en salud y educación. Buenos Aires: Centro de Publicaciones Educativas y Material Didáctico, 2007.

WEEKS, J. Sexualidad. México: Paidós/PUEG-UNAM, 1998.

JONES, D.E. Diálogo entre padres y adolescentes sobre sexualidad: discursos morales y médicos en la reproducción de las desigualdades de género. Interface - Comunic., Saude, Educ., v.14, n.32, p.171-82, jan./mar. 2010.

Las mujeres y los hombres adolescentes construyen determinadas dimensiones de su sexualidad a partir del diálogo con adultos que les transmites valores y normas. El artículo analiza conversaciones sobre sexualidad de adolescentes con sus padres en que se articulan registros discursivos médicos y morales. La investigación se basa en 46 entrevistas individuales con hombres y mujeres de 15 a 19 años de estratos socioeconómicos medios que residen en Trelew, ciudad de 90.00 habitantes de la Patagonia argentina, y cursan enseñanza media. Para explicar las dinámicas diferenciadas de dialogo entre adolescentes mujeres y adolescentes hombres, elaboramos las nociones de control parental de la sexualidad femenina adolescente y omnipresencia material y discursiva del preservativo. Estas nociones muestran como los diálogos con adultos son atravesados por expectativas desiguales de género que, a su vez, ellos mismos refuerzan.

Palabras clave: Adolescentes. Sexualidad. Diálogo con padres. 